
\title{
25 Research Square \\ Enhanced Anti-cancer Effects of Conditioned Medium From Hypoxic Cultured Human Adult Dermal Fibroblasts
}

\section{Kyu-Hyun Han}

Division of Vascular Surgery, Samsung Medical Center, Sungkyunkwan University School of Medicine, Seoul 06351, Republic of Korea

\section{Ae-Kyeong Kim}

Division of Vascular Surgery, Samsung Medical Center, Sungkyunkwan University School of Medicine, Seoul 06351, Republic of Korea

\section{Dong-ik Kim ( $\nabla$ dikim@skku.edu )}

Division of Vascular Surgery, Samsung Medical Center, Sungkyunkwan University School of Medicine, Seoul 06351, Republic of Korea

\section{Research Article}

Keywords: Anti-cancer, Conditioned medium, Fibroblasts, Hypoxic

Posted Date: February 23rd, 2021

DOI: https://doi.org/10.21203/rs.3.rs-221356/v1

License: (c) (1) This work is licensed under a Creative Commons Attribution 4.0 International License. Read Full License 


\section{Abstract}

This study investigates the anti-cancer effects of cervical cancer (HeLa) cells in a conditioned medium (CM) obtained from normoxic and hypoxic cultured human adult dermal fibroblasts (HDFs). The HeLa cells showed decreased cell viability, arrested cell cycles, and increased apoptosis in CM from hypoxic cultured HDFs (H-CM) compared with normoxic cultured HDFs (N-CM). In up-regulated (> 2-fold) proteins of $\mathrm{H}-\mathrm{CM}$ compared with $\mathrm{N}-\mathrm{CM}$, the top enriched term of biological process of gene ontology (GO) was GO:0006955 immune response. In intracellular down-regulated (> 2-fold) proteins of HeLa cells treated with $\mathrm{H}-\mathrm{CM}$ compared with $\mathrm{N}-\mathrm{CM}$, the top enriched term of biological process of $\mathrm{GO}$ was GO:0016579 protein deubiquitination, and the terms of the KEGG pathway were determined to be hsa05166:HTLV-I infection, hsa03410:base-excision repair, and hsa05340:primary immunodeficiency. Among down-regulated hub proteins with $\geq 5$ edges (ESR1 MCL1, TBP, CD19, LCK, PCNA, CHEK1, and POLA1) of HeLa cells treated with H-CM, the top enriched term of biological process of $\mathrm{GO}$ and the KEGG pathway were G0:0006272 leading strand elongation and hsa05166:HTLV-I infection. H-CM displayed not only enhanced anti-cancer effects on HeLa cells compared with $\mathrm{N}-\mathrm{CM}$, but also induced intracellular signaling patterns with 9 hub proteins.

\section{Introduction}

Hypoxic (low oxygen) conditions reportedly induce cancer proliferation or metastasis ${ }^{1,2}$ or cause severe injury in a variety of diseases ${ }^{3-6}$. Beneficial effects of hypoxia have also been reported, in the form of enhanced wound healing ${ }^{7}$, angiogenesis ${ }^{8}$, anti-aging ${ }^{9}$, and anti-cancers effects ${ }^{10}$, depending on the kind of cells.

In the case of fibroblasts, hypoxia plays an important role in construction and repair of organs and tissues by secretory factors and the extracellular matrix (ECM) reorganization ${ }^{11}$, and in cancer initiation, progression, metastasis through direct interaction signaling ${ }^{12}$. When fibroblasts were exposed to hypoxic conditions, contradictory results have been reported. Hypoxic fibroblasts exhibited increased cell viability and proliferation ${ }^{13}$ and stimulated invasive activity of cancer cells $s^{14}$, but proliferation of severely hypoxic fibroblast was regulated ${ }^{15}$, and fibroblast-mediated cancer stiffness and metastasis were impaired ${ }^{16}$.

In a previous study, epithelial cells ${ }^{17}$, mesenchymal stem cells ${ }^{18}$, embryonic stem cells ${ }^{19}$ and immune cells ${ }^{20}$ all suppressed cancer cells. However, the anti-cancer effects of hypoxic fibroblasts have not yet been studied. In this study, we investigated whether a conditioned medium (CM) from hypoxic human adult dermal fibroblast (HDFs) (H-CM), compared with normoxic CM (N-CM) enhanced anti-cancer effects on cervical cancer (HeLa) cells. We also profiled secretory proteins in $\mathrm{H}-\mathrm{CM}$ and determined the intracellular signaling pattern in HeLa cells induced by $\mathrm{H}-\mathrm{CM}$, compared with $\mathrm{N}-\mathrm{CM}$, using protein antibody array analysis.

\section{Results}


Enhanced reduction in cell viability of HeLa cells with $\mathrm{H}-\mathrm{CM}$. The ratio of proliferation cell viability between normoxic and hypoxic HDFs at passage 6 did not change (Fig. 1A, B). Viability of HeLa cells was significantly reduced by $\mathrm{H}-\mathrm{CM}$ treatment compared with $\mathrm{C}-\mathrm{CM}$ or $\mathrm{N}-\mathrm{CM}$ at 48 to $72 \mathrm{~h}$ (Fig. 1C). In contrast, viability of HUVECs was significantly increased by $\mathrm{H}-\mathrm{CM}$ compared with $\mathrm{C}-\mathrm{CM}$ or $\mathrm{N}-\mathrm{CM}$ at $72 \mathrm{~h}$ (Fig. 1D). In the case of HUC-MSCs, viability was increased by both N-CM and $\mathrm{H}-\mathrm{CM}$ compared with C-CM at $48 \mathrm{~h}$, but increased only by N-CM compared with $\mathrm{C}-\mathrm{CM}$ at $72 \mathrm{~h}$, with no statistically significant different evident between $\mathrm{N}-\mathrm{CM}$ and $\mathrm{H}-\mathrm{CM}$ (Fig. 1E).

Increased apoptosis of HeLa cells with H-CM. When HeLa cells were treated for $48 \mathrm{~h}$, the proportion of live cells indicating annexin- $\mathrm{V}(-) / \mathrm{PI}(-)$ significantly decreased. When treated with $\mathrm{H}-\mathrm{CM}$ compared with $\mathrm{C}-\mathrm{CM}$ and $\mathrm{N}-\mathrm{CM}$ (Fig. 2A-B), early apoptotic cells indicating annexin- $\mathrm{V}(+) / \mathrm{PI}(-)$ increased by $\mathrm{N}-\mathrm{CM}$ or $\mathrm{H}-\mathrm{CM}$ compared with C-CM (Fig. 2A-C). Between N-CM and H-CM treatment conditions, early apoptotic cells were decreased by $\mathrm{H}-\mathrm{CM}$ (Fig. 2A-C). Late apoptotic cells indicating annexin- $\mathrm{V}(+) / \mathrm{PI}(+)$ were strongly increased when treated with $\mathrm{H}-\mathrm{CM}$ compared with $\mathrm{N}-\mathrm{CM}$ and C-CM (Fig. 2A-D). The representative apoptotic marker, caspase-3/7 activity in HeLa cells, increased when treated with $\mathrm{H}-\mathrm{CM}$ compared with C$\mathrm{CM}$ and $\mathrm{N}-\mathrm{CM}$ at 12 to $48 \mathrm{~h}$ (Fig. 2E). MMPs of HeLa cells decreased when treated with $\mathrm{N}-\mathrm{CM}$ or $\mathrm{H}-\mathrm{CM}$ compared with $\mathrm{CM}$ at $24 \mathrm{~h}$, and decreased strongly with only $\mathrm{H}-\mathrm{CM}$ compared with $\mathrm{C}-\mathrm{CM}$ and $\mathrm{N}-\mathrm{CM}$ at 48 h (Fig. 2F).

Strongly induced cell-cycle arrest HeLa cells with H-CM. After $24 \mathrm{~h}$ of $\mathrm{CM}$ treatment, cell-cycle arrest of HeLa cells was induced by H-CM compared with C-CM and N-CM. Not only did the G0/G1 phase increase (Fig. 3A-B), but the $S$ phase decreased (Fig. 3A-C) when treated with $\mathrm{H}-\mathrm{CM}$ compared with $\mathrm{C}-\mathrm{CM}$ and $\mathrm{N}$ $\mathrm{CM}$. The G2/M phase did not significantly change after CM treatments (Fig. 3A-D). After $48 \mathrm{~h}$ of $\mathrm{CM}$ treatment, the G0/G1 phase increased strongly (Fig. 3E-F), and the $S$ and G2/M phases decreased strongly (Fig. 3E-H) after treatment with $\mathrm{H}-\mathrm{CM}$ compared with C-CM and N-CM.

Profiling of up- and down-regulated proteins in $\mathrm{H}-\mathrm{CM}$ compared with $\mathrm{N}-\mathrm{CM}$. To investigate secretory proteins in $\mathrm{H}-\mathrm{CM}$ compared with $\mathrm{N}-\mathrm{CM}$, a protein antibody array was performed. Two-fold up-regulated (red) or down-regulated (blue) proteins in $\mathrm{H}-\mathrm{CM}$ compared with $\mathrm{N}-\mathrm{CM}$ were identified among 10,000 proteins of the antibody array. Twenty proteins of up-regulated and down-regulated proteins (>2-fold) were analyzed in $\mathrm{H}-\mathrm{CM}$ compared with N-CM (Fig. 4A, Supplemental Table 1). To categorize up- and down- regulated proteins in H-CM, a GO analysis using DAVID was performed $(p<0.01)$, and the data were described as the $-\log _{10} \mathrm{p}$ value.

In up-regulated proteins, the highest enriched term of biological process of GO was G0:0006955 immune response (8.062). In the next, G0:0006954 inflammatory response (6.948), G0:0007165 signal transduction (5.766), G0:0070374 positive regulation of ERK1 and ERK2 cascade (4.408), G0:0070098 chemokine-mediated signaling pathway (4.175), G0:0050930 induction of positive chemotaxis (3.899), G0:0048754 branching morphogenesis of an epithelial tube (3.520), G0:0043547 $\sim$ positive regulation of GTPase activity (3.478), G0:0006935 chemotaxis (3.478), G0:0050918 positive chemotaxis (3.152), G0:0001666 response to hypoxia (3.043), G0:0002548 monocyte 
chemotaxis (2.993), G0:0001541 ovarian follicle development (2.993), G0:0042127 regulation of cell proliferation (2.951), G0:0071346 cellular response to interferon-gamma (2.729), G0:0009612 response to mechanical stimulus (2.700), GO:0060326 cell chemotaxis (2.617), G0:0030593 neutrophil chemotaxis (2.603), G0:0071347 cellular response to interleukin-1 (2.541), G0:0050729 positive regulation of inflammatory response (2.517), G0:0071356 cellular response to tumor necrosis factor (2.170), G0:0045766 positive regulation of angiogenesis (2.133), G0:0033209 tumor necrosis factor-mediated signaling pathway (2.111), G0:0048842 positive regulation of axon extension involved in axon guidance (2.103), and GO:0019221 cytokine-mediated signaling pathway (2.024) were categorized (Fig. 4B, Supplemental Table 2).

In the case of down-regulated proteins, terms of biological process of GO included G0:0002576 platelet degranulation (6.370), G0:0022617 extracellular matrix disassembly (4.844), G0:0044267 cellular protein metabolic process (4.271), G0:0018149 peptide cross-linking (3.328), G0:0033209 tumor necrosis factor-mediated signaling pathway (2.588), G0:0007596 blood coagulation (2.211), GO:0051918 negative regulation of fibrinolysis (2.185), and G0:0030198 extracellular matrix organization (2.158) (Fig. 4C, Supplemental Table 3).

\section{Profiling of induced intracellular proteins in HeLa cells by $\mathrm{H}-\mathrm{CM}$ compared with $\mathrm{N}-\mathrm{CM}$. To investigate} intracellular signaling patterns of HeLa cells with respect to the enhanced anti-cancer effects of $\mathrm{H}-\mathrm{CM}$ compared with $\mathrm{N}-\mathrm{CM}$, a protein antibody array was performed. Compared with $\mathrm{N}-\mathrm{CM}, \mathrm{H}-\mathrm{CM}$ induced upregulation of 20 proteins and down-regulation of 56 proteins ( $>2$-fold) among 1,358 proteins of the array of HeLa cells (Fig. 5A, Supplemental Table 4). These proteins were categorized by GO analysis and the KEGG pathway using DAVID, and the data were described as the $-\log _{10} \mathrm{p}$ value. In up-regulated proteins, the biological process of GO and the KEGG pathway were not determined. In the $G O$ analysis $(p<0.01)$ of down-regulated proteins, the top enriched term of biological process was G0:0016579 protein deubiquitination (2.448), and the next enriched terms were G0:0042981 regulation of apoptotic process (2.373), G0:0006366 transcription from RNA polymerase II promoter (2.311), and G0:0006272 leading strand elongation (2.033) (Fig. 5B, Supplemental Table 5). In the case of the KEGG pathway ( $p<$ 0.01) of down-regulated proteins, hsa05166:HTLV-I infection (2.422), hsa03410:base-excision repair (2.078), and hsa05340:primary immunodeficiency were determined (2.053). (Fig. 5C, Supplemental Table 5).

PPI network and hub protein selection. To identify PPI and select hub proteins in HeLa cells treated with $\mathrm{H}-\mathrm{CM}$ compared with N-CM, the STRING database and Cytoscape software were used. A total of 47 nodes (proteins) and 74 edges (protein interaction lines) were determined in PPI of up- and down-regulated intracellular proteins in HeLa cells treated with H-CM compared with cells treated with N-CM (Fig. 5D, Table 1). When the interacting proteins had more than 5 edges in PPI, they were defined as hub proteins. Based on this definition, TNF (3.002 + fold), ESR1 (2.142- fold), MCL1 (2.035-fold), TBP (2.355-fold), CD19 (2.257-fold), LCK (2.030-fold), PCNA (2.172-fold), CHEK1 (2.205-fold), and POLA1 (2.022-fold) were determined to be hub proteins (Fig. 5E, Table 1). GO and the KEGG pathway were applied to these hub proteins to determine the signal pathway patterns, and the data are described as the $-\log _{10} \mathrm{p}$ value. 
With only one up-regulated protein, TNF, GO and the KEGG pathway were not determined. In the other 8 down-regulated hub proteins, biological process of $\mathrm{GO}$ analysis included G0:0006272 leading strand elongation (2.903), GO:0006260 DNA replication (2.763), G0:0006271 DNA strand elongation involved in DNA replication (2.205), G0:0016032 viral process (2.204), and G0:0000083 regulation of transcription involved in G1/S transition of mitotic cell cycle (2.020) (Fig. 5F, Table 2), and for the KEGG pathway analysis, only hsa05166:HTLV-I infection (2.807) was determined (Fig. 5G, Table 2). 
Table 1

Nodes and edges in PPI of up- and downregulated intracellular proteins in HeLa cells treated with $\mathrm{H}-\mathrm{CM}$ compared with $\mathrm{N}-\mathrm{CM}$ ( $>2$-fold)

\begin{tabular}{|c|c|c|}
\hline Node & Number of edges & Fold change \\
\hline TNF & 18 & $3.002(+)$ \\
\hline ESR1 & 12 & $2.142(-)$ \\
\hline MCL1 & 7 & $2.035(-)$ \\
\hline TBP & 7 & $2.355(-)$ \\
\hline CD19 & 6 & $2.257(-)$ \\
\hline LCK & 6 & $2.030(-)$ \\
\hline PCNA & 6 & $2.172(-)$ \\
\hline CHEK1 & 5 & $2.205(-)$ \\
\hline POLA1 & 5 & $2.022(-)$ \\
\hline ACTG2 & 4 & $2.338(-)$ \\
\hline APAF1 & 4 & $2.327(-)$ \\
\hline HPRT1 & 4 & $2.468(-)$ \\
\hline PTH & 4 & $2.113(-)$ \\
\hline REN & 4 & $2.297(+)$ \\
\hline USP13 & 4 & $2.200(-)$ \\
\hline BCL10 & 3 & $2.018(-)$ \\
\hline CD8A & 3 & $2.181(-)$ \\
\hline GATA1 & 3 & $2.055(-)$ \\
\hline PLK2 & 3 & $2.206(+)$ \\
\hline ACTR3 & 2 & $2.082(-)$ \\
\hline ADRA2A & 2 & $2.096(-)$ \\
\hline ANXA6 & 2 & $2.433(-)$ \\
\hline ALDH3B1 & 2 & $2.358(-)$ \\
\hline COL3A1 & 2 & $2.315(+)$ \\
\hline ADGRE1 & 2 & $2.042(-)$ \\
\hline HMGB1 & 2 & $2.070(-)$ \\
\hline
\end{tabular}




\begin{tabular}{|lll|}
\hline Node & Number of edges & Fold change \\
\hline S100A6 & 2 & $2.027(-)$ \\
\hline TFAP2A & 2 & $2.465(-)$ \\
\hline POU2F2 & 2 & $2.073(-)$ \\
\hline USP19 & 2 & $2.089(-)$ \\
\hline USP30 & 2 & $2.140(-)$ \\
\hline ADH7 & 1 & $2.264(-)$ \\
\hline DNM1 & 1 & $2.071(-)$ \\
\hline ELK1 & 1 & $2.165(-)$ \\
\hline GAD1 & 1 & $2.075(+)$ \\
\hline GPRIN2 & 1 & $3.252(+)$ \\
\hline GPR18 & 1 & $2.408(-)$ \\
\hline GRTP1 & 1 & $3.786(+)$ \\
\hline IAPP & 1 & $2.501(-)$ \\
\hline IP6K2 & 1 & $2.393(-)$ \\
\hline NFE2L2 & 1 & $2.217(-)$ \\
\hline PTGS1 & 1 & $2.427(+)$ \\
\hline POLL & 1 & $2.090(-)$ \\
\hline TNNI3 & 1 & $2.246(-)$ \\
\hline TNXB & 1 & $2.044(-)$ \\
\hline TUBGCP3 & 1 & $2.331(+)$ \\
\hline USP24 & 1 & $(-)$ \\
\hline
\end{tabular}


Table 2

GO and KEGG pathways of down-regulated hub proteins ( $\geq 5$ edges) in HeLa cells with H-CM compared with N-CM $(p<0.01)$

\begin{tabular}{|c|c|c|c|c|}
\hline DAVID & Category & Term & Protein & $\begin{array}{l}-\log _{10} \\
\text { value }\end{array}$ \\
\hline \multirow[t]{5}{*}{$\begin{array}{l}\text { GO } \\
\text { analysis }\end{array}$} & \multirow[t]{5}{*}{$\begin{array}{l}\text { Biological } \\
\text { process }\end{array}$} & G0:0006272 leading strand elongation & $\begin{array}{l}\text { POLA1, } \\
\text { PCNA }\end{array}$ & 2.903 \\
\hline & & G0:0006260 DNA replication & $\begin{array}{l}\text { POLA1, } \\
\text { PCNA, } \\
\text { CHEK1 }\end{array}$ & 2.763 \\
\hline & & $\begin{array}{l}\text { GO:0006271 DNA strand elongation involved in } \\
\text { DNA replication }\end{array}$ & $\begin{array}{l}\text { POLA1, } \\
\text { PCNA }\end{array}$ & 2.205 \\
\hline & & GO:0016032 viral process & $\begin{array}{l}\text { POLA1, TBP, } \\
\text { LCK }\end{array}$ & 2.204 \\
\hline & & $\begin{array}{l}\text { GO:0000083 regulation of transcription involved } \\
\text { in } \mathrm{G} 1 / \mathrm{S} \text { transition of mitotic cell cycle }\end{array}$ & $\begin{array}{l}\text { POLA1, } \\
\text { PCNA }\end{array}$ & 2.020 \\
\hline \multicolumn{2}{|c|}{$\begin{array}{l}\text { KEGG pathway } \\
\text { analysis }\end{array}$} & hsa05166:HTLV-I infection & $\begin{array}{l}\text { PCNA, TBP, } \\
\text { LCK, CHEK1 }\end{array}$ & 2.807 \\
\hline
\end{tabular}

\section{Discussion}

We demonstrated that $\mathrm{H}-\mathrm{CM}$ treatment resulted in enhanced anti-cancer effects in HeLa cells, profiled secretory proteins in $\mathrm{H}-\mathrm{CM}$ compared with $\mathrm{N}-\mathrm{CM}$, and determined intracellular signaling patterns and hub proteins related to the enhanced anti-cancer effects.

In a previous study, hypoxic culture conditions $\left(1 \%\right.$ or $\left.5 \% \mathrm{O}_{2}\right)$ increased cell viability and proliferation of human pulmonary fibroblasts ${ }^{13}$. Another research team reported that moderate hypoxic conditions ( $2 \%$ $\mathrm{O}_{2}$ ) increased DNA synthesis and proliferation of human lung fibroblasts, whereas severe hypoxic conditions $\left(0.1 \% \mathrm{O}_{2}\right)$ decreased human lung fibroblasts ${ }^{15}$. In our experiment, proliferation of HDFs did not increase in hypoxic culture conditions $\left(1 \% \mathrm{O}_{2}\right)$. These contradictory results may be caused by different kinds of cells or oxygen concentrations of the hypoxic culture condition.

Among up-regulated secretory proteins in $\mathrm{H}-\mathrm{CM}$ compared with $\mathrm{N}-\mathrm{CM}$, researchers have found that IL $37^{21}$, LECT ${ }^{22}$, and TNFSF $15^{23}$ suppress tumor growth, but the other up-regulated proteins were not directly associated with anti-cancer effects. These 3 proteins may be candidates for development of effective anti-cancer drug cocktails.

In intracellular signaling patterns of down-regulated proteins in HeLa cells treated with $\mathrm{H}-\mathrm{CM}$, the terms of biological process of GO analysis included GO:0016579 protein deubiquitination, G0:0042981 regulation of apoptotic process, G0:0006366 transcription from RNA polymerase II promoter, and 
G0:0006272 leading strand elongation. In the case of terms of the KEGG pathway, the highest enriched term was hsa05166:HTLV-I infection, and hsa03410:base-excision repair and hsa05340:primary immunodeficiency were determined. HTLV-I infection plays an essential role in cellular transformation and tumorigenesis from CD4 + T-lymphocytes to adult T-cell leukemia/lymphoma ${ }^{24}$, base-excision repair induced proliferation of prostate cancer ${ }^{25}$, and primary immunodeficiency was related to malignancies in patients ${ }^{26}$. These terms may be considered multiple targets for effective anti-cancer therapies. Based on this knowledge, the relationship between down-regulated proteins and the terms of GO and the KEGG pathway in HeLa cells treated with $\mathrm{H}-\mathrm{CM}$ indicates that, compared with $\mathrm{N}-\mathrm{CM}, \mathrm{H}-\mathrm{CM}$ strongly influences intracellular signaling related to enhanced anti-cancer effects corresponding to our in vitro results, including reduced cell viability, increased apoptosis, and inducement of cell-cycle arrest in HeLa cells.

In a PPI network of up- and down-regulated proteins in HeLa cells treated with H-CM, 1 (TNF) up-regulated and 8 (ESR1, MCL1, TBP, CD19, LCK, PCNA, CHEK1, and POLA1) down-regulated hub proteins were determined by selecting proteins with more than 5 edges. TNF was the only up-regulated hub protein to play an opposite role as a tumor stimulator or suppressor ${ }^{27}$ depending on differences in organs, cells, and carcinogens. As down-regulated hub proteins, ESR $1^{28}, \mathrm{MCL}^{29}{ }^{29} \mathrm{LCK}^{30}, \mathrm{TBP}^{31}$, and $\mathrm{PCNA}{ }^{32}$ play roles in the proliferation or survival of cancer cells, and $\mathrm{CHEK} 1^{33}$ is associated with the cell-cycle checkpoint in cancer cells. In addition, CD $19^{34}$ and POLA $1^{35}$ have been reported to be targets for anti-cancer therapy. The known functions of selected hub proteins are consistent with our data on enhanced anti-cancer effects. Furthermore, the 8 down-regulated hub proteins were categorized as terms including G0:0006272 leading strand elongation, G0:0006260 DNA replication, G0:0006271 DNA strand elongation involved in DNA replication, and GO:0000083 regulation of transcription involved in G1/S transition of the mitotic cell cycle in biological process of GO analysis. Only one term in the KEGG pathway from down-regulated hub proteins was categorized as hsa05166:HTLV-I infection, which was mentioned with respect to tumorigenesis ${ }^{24}$. These terms of GO and the KEGG pathway in down-regulated hub proteins are related to our in vitro results showing enhanced anti-cancer effects of $\mathrm{H}-\mathrm{CM}$ as well.

In our previous study, CM from hypoxic hUC-MSCs showed enhanced anti-cancer effects on HeLa cells, with the exception of $\mathrm{HDFs}^{10}$. In our current study, $\mathrm{H}-\mathrm{CM}$ showed enhanced anti-cancer effects only on HeLa cells, with the exception of HUC-MSCs and HUVECs. These results suggest that hypoxic conditions may be a useful tool to screen candidates for anti-cancer drugs and develop effective anti-cancer therapies. Further study will be required to determine the different effects and mechanisms involved in treatment of HeLa cells and HUC-MSCs or HUVECs with H-CM.

Our study makes it clear that CM from hypoxic HDFs not only enhances anti-cancer effects but also induces anti-cancer-related intracellular signaling patterns and hub proteins related with these effects in HeLa cells. It also suggests that hypoxic culture conditions for HDFs offer a useful alternative approach to developing effective anti-cancer therapies.

\section{Materials And Methods}


Cell culture. Human adult dermal fibroblasts (PromoCell GmbH, Heidelberg, Germany), HeLa cells (ATCC, Manassas, VA, USA) and human umbilical-cord-derived mesenchymal stem cells (HUC-MSCs) (PromoCell GmbH, Heidelberg, Germany) were cultured in Dulbecco's modified Eagle medium (DMEM) supplemented with $10 \%$ fetal bovine serum (FBS, Gibco, Grand Island, NY, USA) and $0.1 \%$ antibiotics (Gibco, Grand Island, NY, USA) at $37^{\circ} \mathrm{C}$ in a $5 \% \mathrm{CO}_{2}$ incubator (APM-30D; ASTEC, Fukuoka, Japan) ${ }^{10}$. Human umbilical vein endothelial cells (HUVECs) (Lonza, Warkerville, MD, USA) were cultured in endothelial cell growth medium-2 (PromoCell GmbH, Heidelberg, Germany). An oxygen level of $21 \%$ as a normoxic condition and $1 \% \mathrm{O}_{2}$ as a hypoxic condition were applied to the culture condition of HDFs from passage 4 to passage $6^{10}$. When cell confluency of all cells reached $90 \%$, the cells were passaged using $0.25 \%$ Trypsin-EDTA (Gibco, Grand Island, NY, USA). For the proliferation assay of both culture conditions of HDFs, $2 \times 10^{5} \mathrm{HDFs}$ at passage 6 were cultured in a 100-mm culture plate for 5 days, and cell numbers were measured using Trypan blue $0.5 \%$ solution (Biowest, Riverside, MO, USA) staining ${ }^{10}$.

Preparation of CM from normoxic and hypoxic HDFs. Normoxic and hypoxic HDFs $\left(2 \times 10^{5}\right.$ cells) at passage 6 were cultured in 100-mm culture plates with complete medium. When cell confluency reached $90 \%$ at day 5 , the cultured medium was removed and $1 \times$ phosphate-buffered saline (PBS) was added to wash the cells. Next, $6 \mathrm{~mL}$ of DMEM without FBS or antibiotics was added to the cells. After incubation for $24 \mathrm{~h}, \mathrm{~N}-\mathrm{CMs}$ and $\mathrm{H}-\mathrm{CMs}$ were harvested and centrifuged at $300 \mathrm{~g}$ for 5 minutes. The supernatant was transferred to new $15 \mathrm{~mL}$ tubes and stored at $-80^{\circ} \mathrm{C}$. For a control, CM (C-CM), DMEM without FBS or antibiotics was used ${ }^{10}$.

Cell viability assay. Normoxic and hypoxic HDFs $\left(1 \times 10^{3}\right.$ cells $)$ at passage 6 were seeded in 96-well white plates. After 5 days of culture, $100 \mu \mathrm{L}$ of CellTiter-Glo assay 2.0 reagents (Promega, Madison, WI, USA) was applied to the cells. After $10 \mathrm{~min}$ of incubation, the luminescence ratio indicating cell viability was measured using a GLOMAX Multi Detection System (Promega Biosystems Sunnyvale, CA, USA) ${ }^{10}$. For analysis of HeLa cell viability and HUC-MSCs and HUVECs treated with CM from HDFs, $1 \times 10^{4}$ cells were seeded in 96-well white plates. The cultured medium was removed the following day and CMs were applied to the cells. After 48 or $72 \mathrm{~h}$, the same procedure using CellTiter-Glo assay 2.0 reagents (Promega, Madison, WI, USA) was followed ${ }^{10}$.

Apoptosis assay. HeLa cells $\left(1.5 \times 10^{5}\right)$ were seeded in 6-well culture plates ${ }^{10}$. The next day, the culture medium was removed and cells were treated with $2 \mathrm{~mL}$ of C-CM, N-CM and $\mathrm{H}-\mathrm{CM}$. After $48 \mathrm{~h}$ of incubation, the cells were harvested with $0.25 \%$ Trypsin-EDTA (Gibco, Grand Island, NY, USA) and stained with a fluorescein isothiocyanate annexin-V apoptosis Detection Kit I (BD Pharmingen, San Diego, CA, USA). Stained cells were analyzed with a caliber flow cytometer (Becton-Dickinson, San Jose, CA, USA) and Flowjo software (Treestar, San Carlos, CA, USA) ${ }^{10}$.

Caspase $3 / 7$ activity assay. HeLa cells $\left(1 \times 10^{4}\right)$ cells were seeded in 96 -well white plates ${ }^{10}$. The next day, the culture medium was removed and $100 \mu \mathrm{L}$ of $\mathrm{C}-\mathrm{CM}, \mathrm{N}-\mathrm{CM}$ and $\mathrm{H}-\mathrm{CM}$ was applied to the cells. After 12, 24, and $48 \mathrm{~h}$ of incubation, $100 \mu \mathrm{L}$ of Caspase-Glo 3/7 Assay reagent (Promega, Madison, WI, USA) was 
added to the cells, which were then incubated for $1 \mathrm{~h}$. The luminescence ratio indicating caspase $3 / 7$ activity was analyzed using a GLOMAX Multi Detection System (Promega Biosystems Sunnyvale, CA, USA) ${ }^{10}$.

Mitochondrial membrane potential assay. HeLa cells $\left(1 \times 10^{4}\right)$ were seeded in 96 -well clear plates ${ }^{10}$. The culture medium was removed the next day and $100 \mu \mathrm{L}$ of $\mathrm{C}-\mathrm{CM}, \mathrm{N}-\mathrm{CM}$, and $\mathrm{H}-\mathrm{CM}$ was applied to the cells. After 12, 24, and $48 \mathrm{~h}$ of incubation, the cells were stained with an Orange Mitochondrial Membrane Potential Assay Kit (Abcam, Cambridge, UK). The fluorescence ratio (Ex/Em $=540 / 590 \mathrm{~nm}$ ) indicating matrix metalloproteinases (MMPs) was measured using a Mithras ${ }^{2}$ LB 943 Multimode Reader (Berthold Biotechnologies, Bad Wildad, Germany $)^{10}$.

Cell-cycle assay. HeLa cells $\left(1.5 \times 10^{5}\right)$ were seeded in 6 -well culture plates ${ }^{10}$. After overnight incubation, the culture medium was removed and cells were treated with $2 \mathrm{~mL}$ of $\mathrm{C}-\mathrm{CM}, \mathrm{N}-\mathrm{CM}$, and $\mathrm{H}-\mathrm{CM}$. After 24 and $48 \mathrm{~h}$ of incubation, cells were harvested with $0.25 \%$ Trypsin-EDTA and fixed with $70 \%$ alcohol at $4^{\circ} \mathrm{C}$ for $1 \mathrm{~h}$. Fixed cells were stained with $20 \mu \mathrm{g} / \mathrm{mL}$ propidium iodide (PI; Abcam) and 1\% RNase A (QIAGEN, Valencia, CA, USA) for $30 \mathrm{~min}$ at $37^{\circ} \mathrm{C}$. Stained cells were suspended in PBS and analyzed using a FACSVerse flow cytometer (BD Biosciences) and Flowjo software (Treestar, San Carlos, CA, USA) ${ }^{10}$.

Analysis of secretory protein by protein antibody array. Secretory proteins in N-CM and $\mathrm{H}-\mathrm{CM}$ were analyzed using a RayBio Label-based (L-Series) Human L1000 Antibody Array (Raybiotech, Inc., Norcross, GA, USA) by E-biogen (Kyung Hee Business Center, Kyung Hee University, Seoul, Korea), and data were analyzed in Genowiz 4.0 (Ocimum Biosolutions, India) ${ }^{10}$. Up- and down-regulated proteins in H-CM compared with N-CM (>2-fold) were described using UniProt DB, and GO and KEGG pathway of proteins were determined using Database for Annotation, Visualization and Integrated Discovery (DAVID) $(p<$ $0.01)^{10}$.

Analysis of intracellular signaling pathways by protein antibody array. HeLa cells $\left(2 \times 10^{5}\right)$ cells were cultured in 100-mm culture plates with complete medium. When cell confluency reached $90 \%$, the culture medium was removed and 1× PBS was added to wash the cells. After removing the PBS, $10 \mathrm{~mL}$ of $\mathrm{N}-\mathrm{CM}$ and $\mathrm{H}-\mathrm{CM}$ was applied to the cells for $24 \mathrm{~h}$. The cells were then harvested and intracellular proteins analyzed with a Signaling Explorer antibody array (Full Moon BioSystems, Sunnyvale, CA, USA) by Ebiogen (Kyung Hee Business Center, Kyung Hee University, Seoul, Korea) ${ }^{10}$. The data were analyzed using Genowiz 4.0), and up- and down-regulated proteins were described using UniProt DB. GO and the KEGG pathways of up- and down-regulated proteins were analyzed using DAVID $(p<0.01)^{10}$. Protein-protein interaction (PPI) was analyzed using the STRING database (string-db.org) and Cytoscape software (www.cytoscape.org). The number of nodes (protein) and edge (protein interaction line) were analyzed, and nodes with more than 5 edges in PPI were defined as hub proteins.

Statistical analysis. All experimental data were analyzed by the t test. A p value $<0.05$ was considered statistically significant. All analyses were carried out using GraphPad Prism version 6.01 (San Diego, CA, USA). 


\section{Declarations}

\section{Data availability}

The datasets generated and/or analyzed during the current study are available from the corresponding author on reasonable request.

\section{Acknowledgments}

This research was supported by the National Research Foundation of Korea (NRF) funded by the Ministry of Science and ICT (NRF-2018M3A9E2023255), and by Basic Science Research Program through the National Research Foundation of Korea (NRF) funded by the Ministry of Education (2016R1A6A3A11935666).

\section{Author contributions}

Kyu-Hyun Han: Study design, performing experiments, interpretation of data, and manuscript writing and review. Ae-Kyeong Kim: performing experiments, interpretation of data. Dong-ik Kim: Study design, interpretation of data, manuscript writing and review, supervision. All authors read and approved the manuscript.

\section{Conflicts of interest}

The authors declare no potential conflict of interest.

\section{References}

1. Joseph, J. P., Harishankar, M. K., Pillai, A. A. \& Devi, A. Hypoxia induced EMT: A review on the mechanism of tumor progression and metastasis in OSCC. Oral Oncol 80, 23-32, http://doi.org/10.1016/j.oraloncology.2018.03.004 (2018).

2. Zhang, T., Suo, C., Zheng, C. \& Zhang, H. Hypoxia and Metabolism in Metastasis. Adv Exp Med Biol 1136, 87-95, http://doi.org/10.1007/978-3-030-12734-3_6 (2019).

3. Abe, H., Semba, H. \& Takeda, N. The Roles of Hypoxia Signaling in the Pathogenesis of Cardiovascular Diseases. J Atheroscler Thromb 24, 884-894, http://doi.org/10.5551/jat.RV17009 (2017).

4. Evans, R. G. Introduction: Renal Hypoxia in Kidney Disease. Semin Nephro/ 39, 517-519, http://doi.org/10.1016/j.semnephrol.2019.10.001 (2019).

5. Jha, N. K. et al. Hypoxia-Induced Signaling Activation in Neurodegenerative Diseases: Targets for New Therapeutic Strategies. J Alzheimers Dis 62, 15-38, http://doi.org/10.3233/jad-170589 (2018).

6. Lyzogub, V. H., Savchenko, O. V., Zaval's'ka, T. V., Dykukha, I. S. \& Loziuk, M. O. [Impact of arterial stiffness on cardiovascular disease and hypoxia]. Lik Sprava, 11-20 (2011). 
7. Sylakowski, K., Bradshaw, A. \& Wells, A. Mesenchymal Stem Cell/Multipotent Stromal Cell Augmentation of Wound Healing: Lessons from the Physiology of Matrix and Hypoxia Support. Am J Pathol 190, 1370-1381, http://doi.org/10.1016/j.ajpath.2020.03.017 (2020).

8. Han, K. H. et al. Enhancement of angiogenic effects by hypoxia-preconditioned human umbilical cord-derived mesenchymal stem cells in a mouse model of hindlimb ischemia. Cell Biol Int 40, 27-35, http://doi.org/10.1002/cbin.10519 (2016).

9. Gorissen, B. et al. Hypoxia negatively affects senescence in osteoclasts and delays osteoclastogenesis. J Cell Physio/ 234, 414-426, http://doi.org/10.1002/jcp.26511 (2018).

10. Han, K. H. et al. Enhanced Anti-Cancer Effects of Conditioned Medium from Hypoxic Human Umbilical Cord-Derived Mesenchymal Stem Cells. Int J Stem Cells 12, 291-303, http://doi.org/10.15283/ijsc19002 (2019).

11. Dick, M. K., Miao, J. H. \& Limaiem, F. in StatPearls (StatPearls Publishing Copyright (C) 2020, StatPearls Publishing LLC., 2020).

12. Kalluri, R. The biology and function of fibroblasts in cancer. Nat Rev Cancer 16, 582-598, http://doi.org/10.1038/nrc.2016.73 (2016).

13. Senavirathna, L. K. et al. Hypoxia induces pulmonary fibroblast proliferation through NFAT signaling. Sci Rep 8, 2709, http://doi.org/10.1038/s41598-018-21073-x (2018).

14. Ide, T. et al. Tumor-stromal cell interaction under hypoxia increases the invasiveness of pancreatic cancer cells through the hepatocyte growth factor/c-Met pathway. Int J Cancer 119, 2750-2759, http://doi.org/10.1002/ijc.22178 (2006).

15. Mizuno, S. et al. Hypoxia regulates human lung fibroblast proliferation via p53-dependent and independent pathways. Respir Res 10, 17, http://doi.org/10.1186/1465-9921-10-17 (2009).

16. Madsen, C. D. et al. Hypoxia and loss of PHD2 inactivate stromal fibroblasts to decrease tumour stiffness and metastasis. EMBO Rep 16, 1394-1408, http://doi.org/10.15252/embr.201540107 (2015).

17. Niknejad, H., Khayat-Khoei, M., Peirovi, H. \& Abolghasemi, H. Human amniotic epithelial cells induce apoptosis of cancer cells: a new anti-tumor therapeutic strategy. Cytotherapy 16, 33-40, http://doi.org/10.1016/j.jcyt.2013.07.005 (2014).

18. Bu, S. et al. Human endometrial mesenchymal stem cells exhibit intrinsic anti-tumor properties on human epithelial ovarian cancer cells. Sci Rep 6, 37019, http://doi.org/10.1038/srep37019 (2016).

19. Liu, J. et al. Embryonic Stem Cells Modulate the Cancer-Permissive Microenvironment of Human Uveal Melanoma. Theranostics 9, 4764-4778, http://doi.org/10.7150/thno.33139 (2019).

20. Gun, S. Y., Lee, S. W. L., Sieow, J. L. \& Wong, S. C. Targeting immune cells for cancer therapy. Redox Biol 25, 101174, http://doi.org/10.1016/j.redox.2019.101174 (2019).

21. Li, Y. et al. Intracellular mature IL-37 suppresses tumor metastasis via inhibiting Rac1 activation. Oncogene 37, 1095-1106, http://doi.org/10.1038/onc.2017.405 (2018). 
22. Ong, H. T. et al. The tumor suppressor function of LECT2 in human hepatocellular carcinoma makes it a potential therapeutic target. Cancer Gene Ther 18, 399-406, http://doi.org/10.1038/cgt.2011.5 (2011).

23. Zhou, J. et al. LITAF and TNFSF15, two downstream targets of AMPK, exert inhibitory effects on tumor growth. Oncogene 30, 1892-1900, http://doi.org/10.1038/onc.2010.575 (2011).

24. Zhang, L. L., Wei, J. Y., Wang, L., Huang, S. L. \& Chen, J. L. Human T-cell lymphotropic virus type 1 and its oncogenesis. Acta Pharmaco/ Sin 38, 1093-1103, http://doi.org/10.1038/aps.2017.17 (2017).

25. Vasquez, J. L. et al. Inhibition of base excision repair by natamycin suppresses prostate cancer cell proliferation. Biochimie 168, 241-250, http://doi.org/10.1016/j.biochi.2019.11.008 (2020).

26. Hauck, F., Voss, R., Urban, C. \& Seidel, M. G. Intrinsic and extrinsic causes of malignancies in patients with primary immunodeficiency disorders. J Allergy Clin Immunol 141, 59-68.e54, http://doi.org/10.1016/j.jaci.2017.06.009 (2018).

27. Wang, X. \& Lin, Y. Tumor necrosis factor and cancer, buddies or foes? Acta Pharmacol Sin 29, 12751288, http://doi.org/10.1111/j.1745-7254.2008.00889.x (2008).

28. Wang, S. et al. Genome-Wide Investigation of Genes Regulated by ERa in Breast Cancer Cells. Molecules 23, http://doi.org/10.3390/molecules23102543 (2018).

29. Kotschy, A. et al. The MCL1 inhibitor $\mathbf{S 6 3 8 4 5}$ is tolerable and effective in diverse cancer models. Nature 538, 477-482, http://doi.org/10.1038/nature19830 (2016).

30. Talab, F., Allen, J. C., Thompson, V., Lin, K. \& Slupsky, J. R. LCK is an important mediator of B-cell receptor signaling in chronic lymphocytic leukemia cells. Mol Cancer Res 11, 541-554, http://doi.org/10.1158/1541-7786.Mcr-12-0415-t (2013).

31. Johnson, S. A. S. et al. Elevated TATA-binding protein expression drives vascular endothelial growth factor expression in colon cancer. Oncotarget 8, 48832-48845, http://doi.org/10.18632/oncotarget.16384 (2017).

32. Juríková, M., Danihel, L'., Polák, Š. \& Varga, I. Ki67, PCNA, and MCM proteins: Markers of proliferation in the diagnosis of breast cancer. Acta Histochem 118, 544-552, http://doi.org/10.1016/j.acthis.2016.05.002 (2016).

33. Wu, M. et al. The clinical significance of CHEK1 in breast cancer: a high-throughput data analysis and immunohistochemical study. Int J Clin Exp Pathol 12, 1-20 (2019).

34. Kochenderfer, J. N. \& Rosenberg, S. A. Treating B-cell cancer with T cells expressing anti-CD19 chimeric antigen receptors. Nat Rev Clin Oncol 10, 267-276, http://doi.org/10.1038/nrclinonc.2013.46 (2013).

35. Cincinelli, R. et al. Novel adamantyl retinoid-related molecules with POLA1 inhibitory activity. Bioorg Chem 104, 104253, http://doi.org/10.1016/j.bioorg.2020.104253 (2020).

\section{Figures}


A

Proliferation

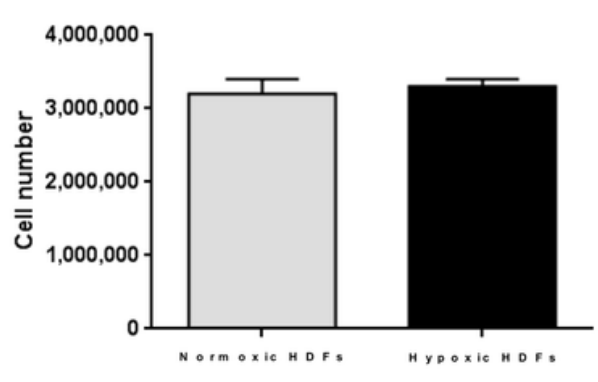

C

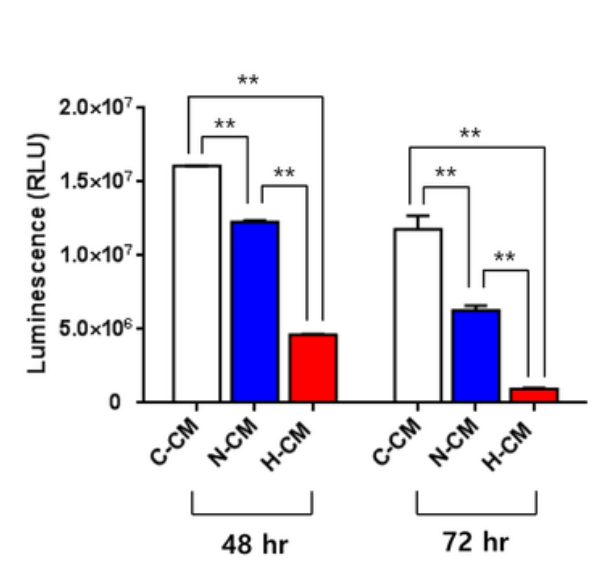

HeLa
B

Cell viability

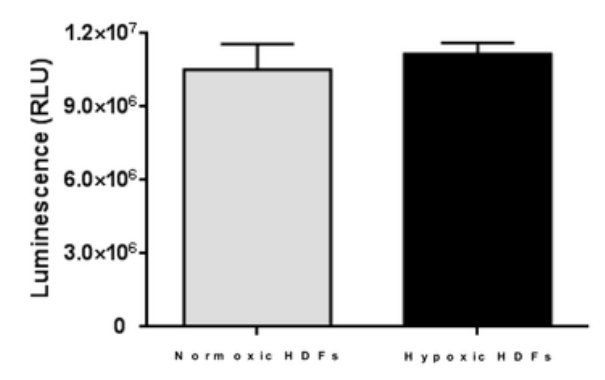

E

HUC-MSC

D

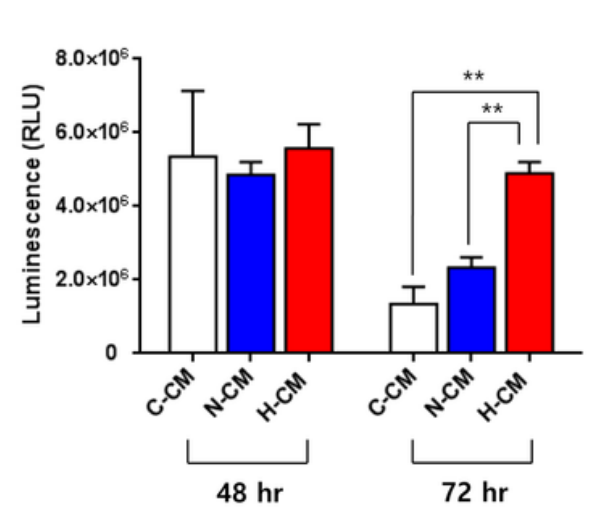

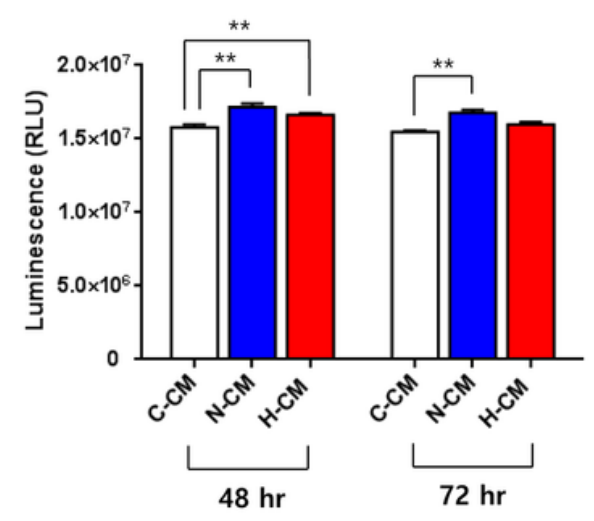

Figure 1

$\mathrm{H}-\mathrm{CM}$ decreased the cell viability of HeLa cells. Proliferation and cell viability of hypoxic and normoxic HDFs did not change after 5 days of culture (A, B). When HeLa cells were treated with CM, cell viability strongly decreased with $\mathrm{H}-\mathrm{CM}$ compared with $\mathrm{C}-\mathrm{CM}$ and $\mathrm{N}-\mathrm{CM}$ after $72 \mathrm{~h}$ treatment (C). Cell viability of HUVEC cells increased with treatment with $\mathrm{H}-\mathrm{CM}$ compared with $\mathrm{C}-\mathrm{CM}$ and $\mathrm{N}-\mathrm{CM}$ (D). Cell viability of HUC-MSCs did not change between N-CM and H-CM treatment (E). Results are expressed as mean $\pm \mathrm{SEM}$ in 3 independent experiments $\left(n=3,{ }^{\star} p<0.05,{ }^{*} p<0.01\right.$, t-test). C-CM, serum-free medium as control; $N$ $\mathrm{CM}$, conditioned medium from normoxic HDFs; $\mathrm{H}-\mathrm{CM}$, conditioned medium from hypoxic HDFs. 
A
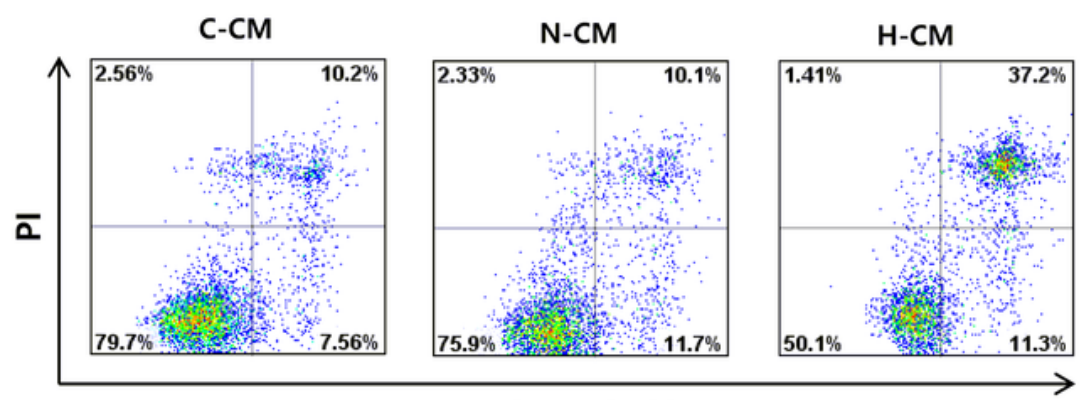

Annexin-V

B

Live cell

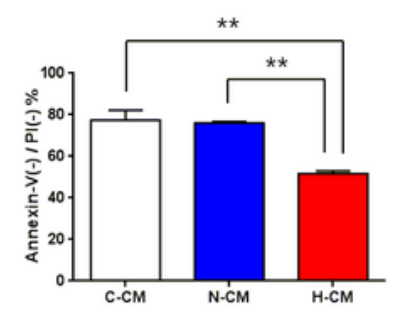

$\mathbf{E}$

Caspase $3 / 7$ activity

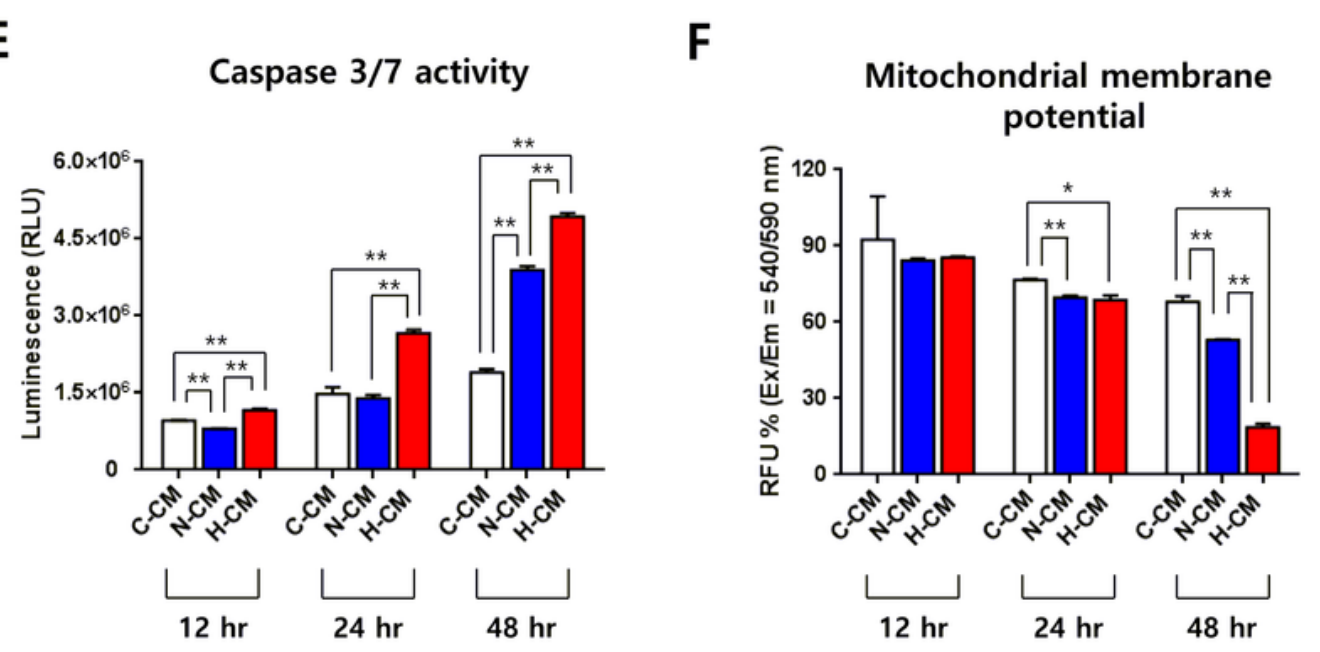

Early apoptosis

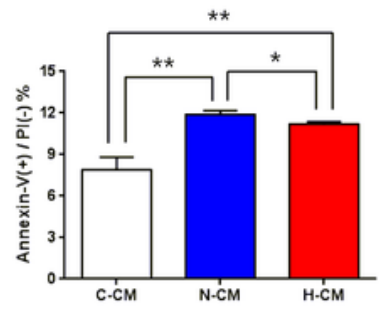

D

Late apoptosis/dead

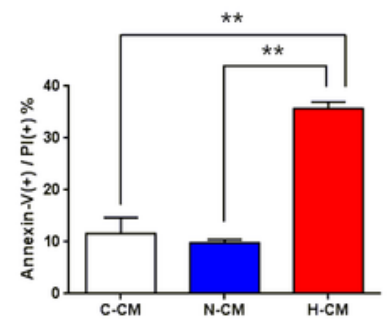

\section{Figure 2}

$\mathrm{H}-\mathrm{CM}$ increased apoptosis of HeLa cells. When HeLa cells were treated with $\mathrm{CM}$ for $48 \mathrm{~h}$, the proportion of live cells [annexin (-)/PI(-)] was strongly decreased with $\mathrm{H}-\mathrm{CM}$ compared with $\mathrm{C}-\mathrm{CM}$ and $\mathrm{N}-\mathrm{CM}(\mathrm{C})(\mathrm{A}, \mathrm{B})$. The proportion of early apoptotic cells [Annexin (+)/PI(-)] was strongly increased with $\mathrm{N}-\mathrm{CM}$ and $\mathrm{H}-\mathrm{CM}$ compared with $\mathrm{C}-\mathrm{CM}(\mathrm{C})$. The proportion of late apoptotic cells [Annexin (+)/PI(+)] was strongly increased with $\mathrm{H}-\mathrm{CM}$ compared with C-CM and N-CM (D). Caspase-3/7 activity in HeLa cells increased when the 
cells were treated with $\mathrm{H}-\mathrm{CM}$ compared with $\mathrm{C}-\mathrm{CM}$ and $\mathrm{N}-\mathrm{CM}$ at 12 to $48 \mathrm{~h}$ of treatment with $\mathrm{CM}(\mathrm{E})$. MMPs in HeLa cells decreased when the cells were treated with $\mathrm{H}-\mathrm{CM}$ compared with $\mathrm{C}-\mathrm{CM}$ and $\mathrm{N}-\mathrm{CM}$ at $48 \mathrm{~h}$ of treatment $(F)$. Results are expressed as mean \pm S.M in 3 independent experiments $(n=3, * p<$ $0.05,{ }^{*} \mathrm{p}<0.01$, t-test). C-CM, serum-free medium as control; $\mathrm{N}-\mathrm{CM}$, conditioned medium from normoxic HDFs; $\mathrm{H}-\mathrm{CM}$, conditioned medium from hypoxic HDFs.

A

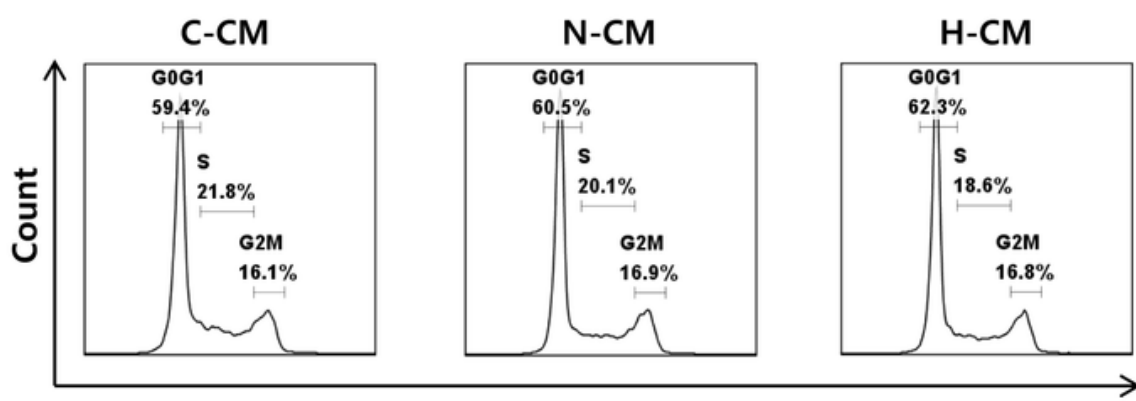

PI (DNA content)

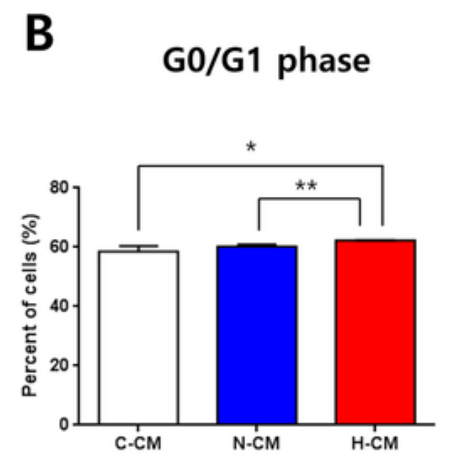

C

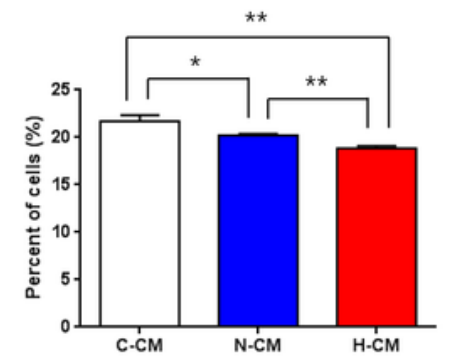

D G2/M phase

E

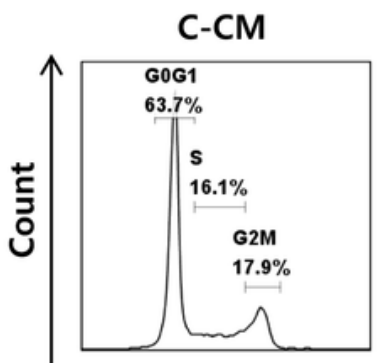

$\mathrm{N}-\mathrm{CM}$
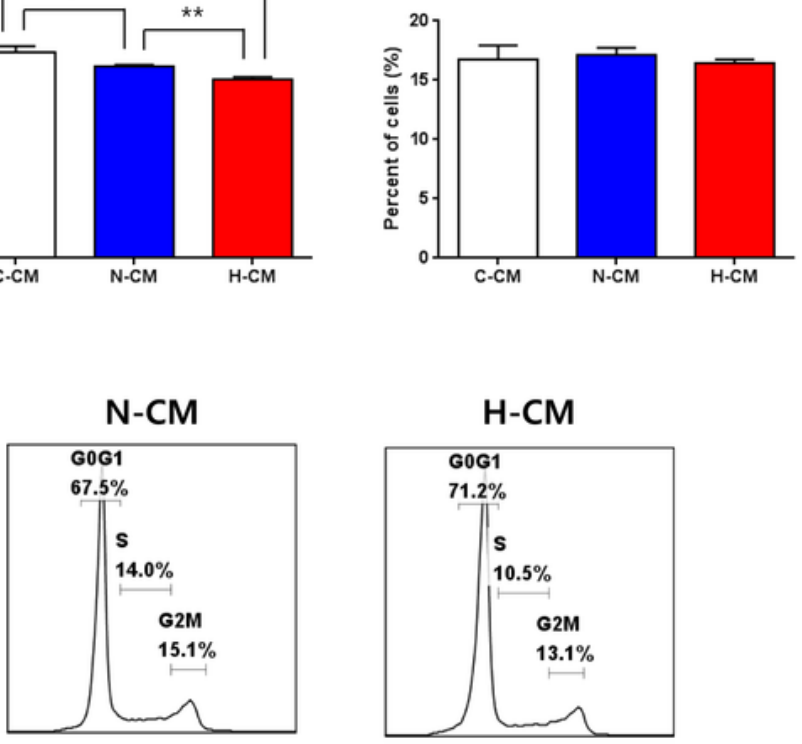

PI (DNA content)

F

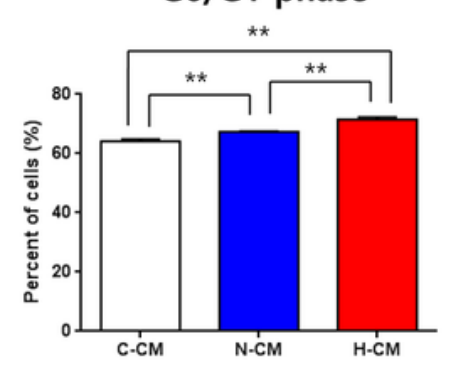

G

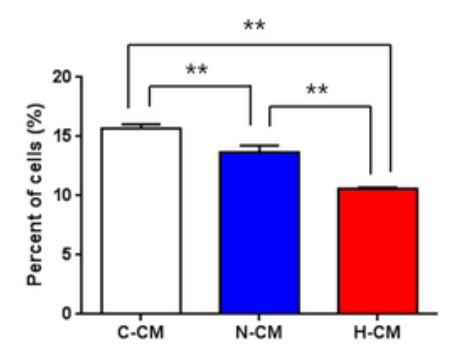

H

$\mathrm{H}-\mathrm{CM}$

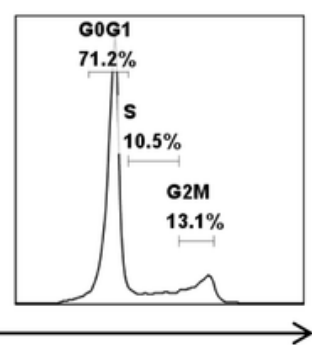

$\longrightarrow$ 
$\mathrm{H}-\mathrm{CM}$ strongly induced cell-cycle arrest of HeLa cells. At $24 \mathrm{~h}$ of treatment with $\mathrm{CM}$ on HeLa cells, the G0/G1 phase increased with $\mathrm{N}-\mathrm{CM}$ and $\mathrm{H}-\mathrm{CM}$ treatment compared with $\mathrm{C}-\mathrm{CM}$ treatment $(\mathrm{A}, \mathrm{B})$. The $\mathrm{S}$ phase decreased with $\mathrm{H}-\mathrm{CM}$ treatment compared with $\mathrm{C}-\mathrm{CM}$ and $\mathrm{N}-\mathrm{CM}$ treatment $(\mathrm{A}, \mathrm{C})$. The $\mathrm{G} 2 / \mathrm{M}$ phase did not change with any $\mathrm{CM}$ treatment $(\mathrm{A}, \mathrm{D})$. At $48 \mathrm{~h}$ of treatment, the G0/G1 phase increased when the cells were treated with $\mathrm{H}-\mathrm{CM}$ compared with $\mathrm{C}-\mathrm{CM}$ and $\mathrm{N}-\mathrm{CM}(\mathrm{E}, \mathrm{F})$. The $\mathrm{S}$ phase decreased when cells were treated with $\mathrm{H}-\mathrm{CM}$ compared with $\mathrm{C}-\mathrm{CM}$ and $\mathrm{N}-\mathrm{CM}(\mathrm{E}, \mathrm{G})$. The $\mathrm{G} 2 / \mathrm{M}$ phase decreased with $\mathrm{H}-\mathrm{CM}$ treatment compared with $\mathrm{C}-\mathrm{CM}$ and $\mathrm{N}-\mathrm{CM}(\mathrm{E}, \mathrm{H})$. Results are expressed as mean $\pm \mathrm{SEM}$ in 3 independent experiments $\left(n=3,{ }^{*} p<0.05,{ }^{*} p<0.01\right.$, t-test). C-CM, serum-free medium as control; N-CM, conditioned medium from normoxic HDFs; $\mathrm{H}-\mathrm{CM}$, conditioned medium from hypoxic HDFs. 
Up- and down-regulated proteins

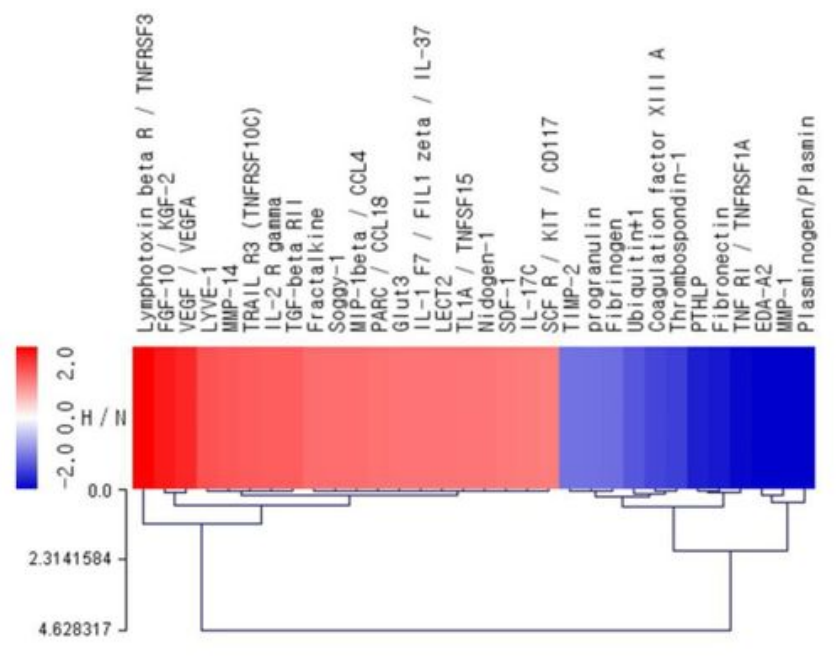

B

Biological process of up-regulated proteins

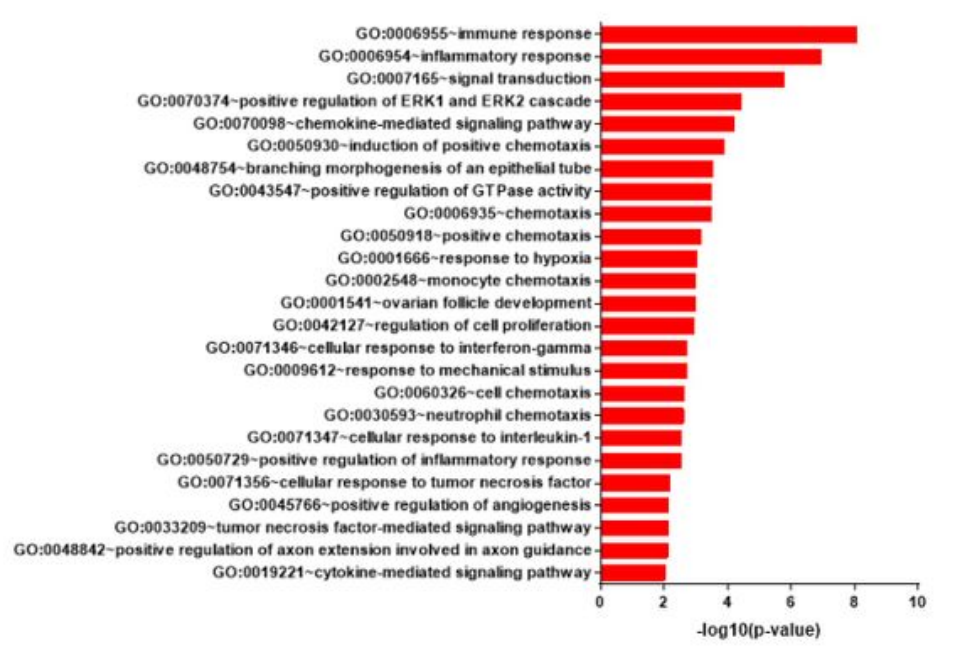

Biological process of down-regulated proteins

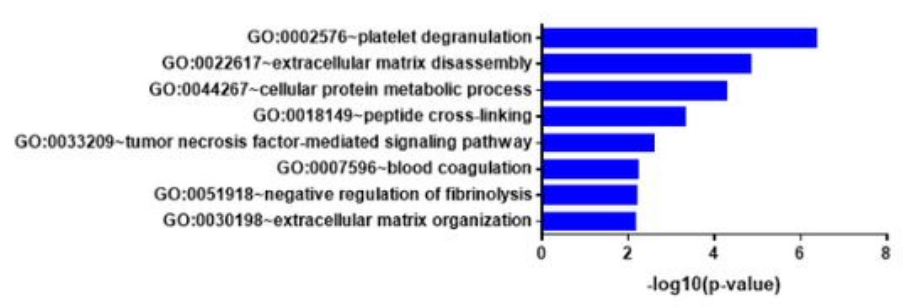

\section{Figure 4}

Up- and down-regulated proteins in H-CM compared with N-CM. Clustering image of up-(red) and downregulated (blue) proteins in $\mathrm{H}-\mathrm{CM}$ compared with $\mathrm{N}-\mathrm{CM}$ were analyzed using a protein antibody array (> 2fold) (A). Biological process of GO analysis of up-regulated proteins in H-CM compared with $\mathrm{N}-\mathrm{CM}(\mathrm{B})$. Biological process of GO analysis for down-regulated proteins in H-CM compared with N-CM (C). The 
data of G0 are represented by the $-\log 10 p$ value $(p<0.01)$. Red color, up-regulated proteins; Blue color, down-regulated proteins.

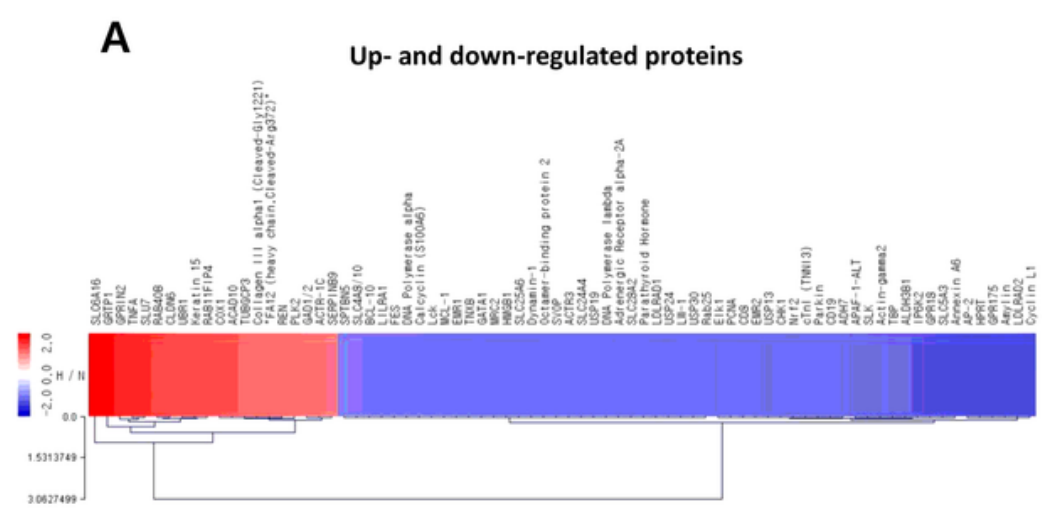

B

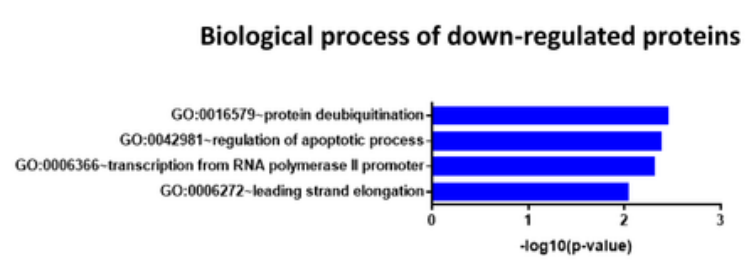

D PPI nework

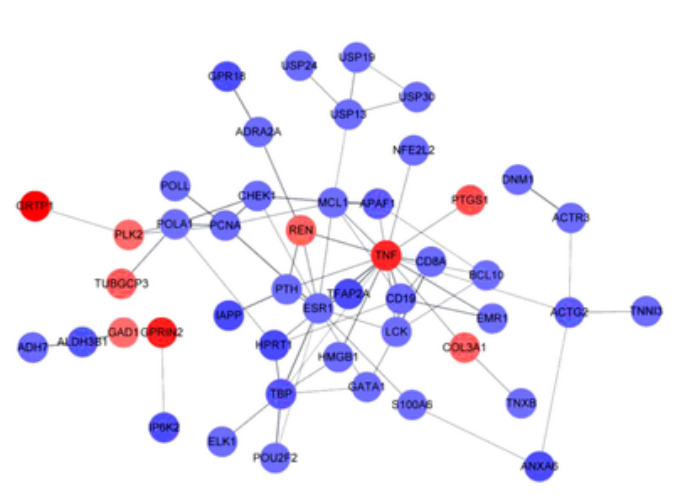

$\mathbf{F}$

Biological process of down-regulated hub proteins

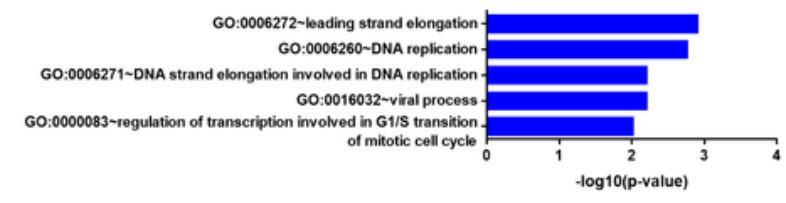

C

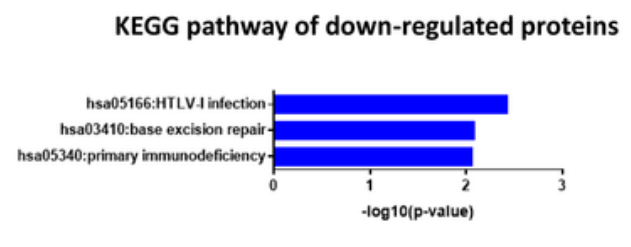

$\mathbf{E}$ Hub proteins

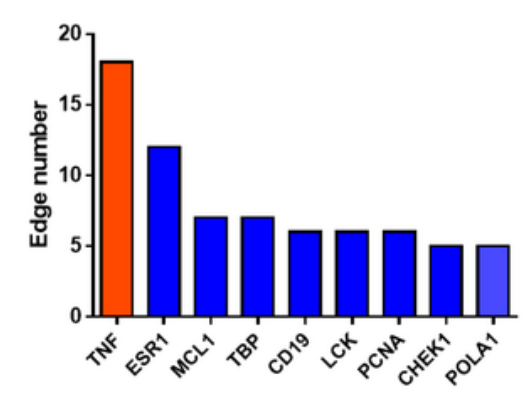

G KEGG pathway of down-regulated hub proteins

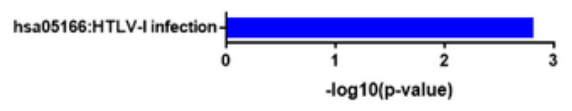

\section{Figure 5}

Profiling of intracellular signaling and selection of hub proteins in HeLa cells with $\mathrm{H}-\mathrm{CM}$ compared with $\mathrm{N}$ CM. Up- (red) and down-regulated (blue) intracellular proteins in HeLa cells treated with H-CM compared with $\mathrm{N}-\mathrm{CM}$ according to a protein antibody array analysis (>2-fold) (A). Biological process of $\mathrm{GO}$ analysis 
of down-regulated proteins in HeLa cells treated with H-CM compared with N-CM (B). The KEGG pathway analysis of down-regulated proteins in HeLa cells treated with $\mathrm{H}-\mathrm{CM}$ compared with N-CM (C). PPI network in up- and down-regulated intracellular proteins of HeLa cells treated with $\mathrm{H}-\mathrm{CM}$ compared with $\mathrm{N}-\mathrm{CM}(\mathrm{D})$. Hub proteins ( $\geq 5$ edges) in PPI of up- and down-regulated intracellular proteins in HeLa cells treated with $\mathrm{H}-\mathrm{CM}$ compared with $\mathrm{N}-\mathrm{CM}(\mathrm{E})$. The biological process of $\mathrm{GO}$ analysis of down-regulated hub proteins in HeLa cells treated with H-CM compared with N-CM (F). The KEGG pathway analysis of downregulated hub proteins in HeLa cells treated with $\mathrm{H}-\mathrm{CM}$ compared with $\mathrm{N}-\mathrm{CM}(\mathrm{G})$. The data for $\mathrm{GO}$ and KEGG pathway results are represented as the $-\log 10 p$ value $(p<0.01)$. Red color, up-regulated proteins; Blue color, down-regulated proteins; PPI, protein-protein interaction.

\section{Supplementary Files}

This is a list of supplementary files associated with this preprint. Click to download.

- SupplementaryTables.docx 